\title{
Development and optimization of a HPLC-RI method for the determination of major sugars in apple juice and evaluation of the effect of the ripening stage
}

\author{
Acácio Antonio Ferreira ZIELINSKI ${ }^{1}$, Cíntia Maia BRAGA ${ }^{1}$, Ivo Mottin DEMIATE ${ }^{1 *}$, \\ Flávio Luís BELTRAME ${ }^{2}$, Alessandro NOGUEIRA ${ }^{1}$, Gilvan WOSIACKI ${ }^{1}$
}

\begin{abstract}
The sugars in apple juice prove its authenticity and its sensory and nutritional properties. The aim of this study was to develop and validate a simple analytical method using high performance liquid chromatography with refractive index detection (HPLC-RI) to determinate and quantify the sugars sucrose, D-glucose, D-fructose, and D-sorbitol polyol in apple juices, as well as to analyze the juices from the Fuji Suprema and Lis Gala cultivars at three ripening stages. The analytical performance parameters evaluated indicated that the method was specific for the compounds analyzed, and the linearity of the calibration curves of sugars showed high correlation coefficients (close to 1.0). The limits of detection and quantification are consistent with recommendations available in the literature for this type of matrix. Sample preparation is simple and generates small amount of residues. Over $70 \%$ of the sugars were determined in the juices of apples at the pre-ripe stage, with an increase during senescence. This method is applicable for the determination of sugars in juices and evaluation of apple ripening.
\end{abstract}

Keywords: Malus domestica; soluble carbohydrates; liquid chromatography; validation.

\section{Introduction}

Apple, one of the most widely consumed fruits worldwide, is an important part of the human diet as a source of monosaccharides, minerals, dietary fibers, biological active compounds such as vitamin $\mathrm{C}$, and phenolic compounds that act as natural antioxidants (Wu et al., 2007). Among the temperate fruits grown in Brazil, it has shown the highest growth in terms of planted area and production volume over the last twenty years. Most of the apple production is concentrated in the Southern region of Brazil, and the state of Santa Catarina is the largest producer, followed by Rio Grande do Sul and Paraná. The apple varieties most commonly grown in Brazil are of 'Gala' and 'Fuji' cultivars, which represent 55\% and $40 \%$ of production, respectively (Associação Brasileira de Produtores de Maçã, 2007; Zielinski et al., 2012).

According to the Ministry of Agriculture, Livestock and Supply, apple juice is defined as "an unfermented and undiluted drink obtained from the edible part of the apple (Malus domestica B.) through appropriate technological processes" (Brasil, 2009).

Common adulteration of apple juice involves the addition of water, sucrose, bagasse extract, or cheaper juices. Besides compromising the proof of authenticity, this also has an effect on the sensory properties and nutritional value of the apple products (Wu et al., 2007; Wosiacki et al., 2007). The major carbohydrates found in apple juice are the sugars sucrose, D-glucose, and D-fructose and the polyol, D-sorbitol (Wosiacki et al., 2007; Hecke et al., 2006).

Several methods have been used for the determination of sugars in fruit and fruit juices, including spectrophotometry
(Llamas et al., 2011; Rodriguez-Saona et al., 2001), capillary electrophoresis (Soga \& Serwe, 2000), and gas chromatography (GC) (Villamiel et al., 1998; Cerdán-Calero, 2012). Although gas chromatography is a separation method with high sensitivity, it requires time-consuming derivative stages, often using toxic agents in the process. Moreover, high temperatures are required for analysis (Chinnici et al., 2005).

Due to its simplicity, accuracy, and ease of sample preparation (involving only dilution and filtration stages as pre-treatment of the sample), high performance liquid chromatography (HPLC) has become popular because it provides a rapid quantitative separation of the main sugars in fruit juices (Chinnici et al., 2005; Lima et al., 2010).

In recent years, several researchers have emphasized the use of the HPLC technique for its high precision and analytical selectivity for the evaluation of diverse food components owing to its ability to determine and quantify these components in many different foods. Among the components determined using HPLC are carbohydrates (Chávez-Servín et al., 2004; Muir et al., 2009), organic acids (Chinnici et al., 2005; Lima et al., 2010), lipids (Puoci et al., 2008), vitamins (Speek et al., 1986; Rodriguez et al., 2012), colorants (Vidotti, et al., 2006; Ma et al., 2006), amino acids and peptides (Zhang et al., 2010; Garai-Ibade et al., 2012), mycotoxins (Kawashima \& Soares, 2006), and phenolic compounds (Shui \& Leong, 2002; AcostaMontoya et al., 2010), among others.

This study presents the development and validation of an analytical method employing the HPLC-RI technique for the rapid and simultaneous determination of sucrose, D-glucose,

\footnotetext{
Received 13 May, 2013

Accepted 24 Nov., 2013 (006091)

${ }^{1}$ Food Science and Technology Graduate Program, State University of Ponta Grossa - UEPG, Ponta Grossa, PR, Brazil, e-mail: demiate@yahoo.com

${ }^{2}$ Department of Pharmaceutical Sciences, State University of Ponta Grossa - UEPG, Ponta Grossa, PR, Brazil

${ }^{*}$ Corresponding author
} 
D-fructose, and D-sorbitol in apple juice and to evaluate the ripening stages of the apples of the Fuji Suprema and Lis Gala cultivars.

\section{Materials and methods}

\subsection{Materials}

Ultra-purified water (type 1) obtained from Millipore ${ }^{\bullet}$ Milli-Q Integral ${ }^{\circledR}$ system (Millipore, São Paulo, Brazil) was used in all the experiments. The standards, sucrose, D-glucose, D-sorbitol, all with a purity exceeding 99.0\%, were purchased from Sigma Aldrich (Steinheim, Germany), and D-fructose was purchased from Merck (Darmstadt, Germany). A Waters Sugar Pak ${ }^{\mathrm{TM}}$ chromatographic column $1(300 \times 6.5 \mathrm{~mm}$ i.d. $)$ was used in the analyses.

\subsection{Samples}

Samples of Fuji Suprema and Lis Gala apples, 2012 harvest season, were collected from the Caçador Agricultural Research and Rural Extension Company of Santa Catarina (EPAGRI, Santa Catarina, Brazil) at three different ripening stages (preripe, ripe, and senescent), with about $20 \mathrm{~kg}$ of samples for each stage and each cultivar. The maturation index was determined by Lugol's starch test (Llorente et al., 2012).

\subsection{Apple juice processing}

The fruits were selected, cleaned, and then pureed using a food processor (Metvisa, Brusque SC, Brazil). The mashed fruit was wrapped in plastic sheets (with pre-punched holes) overlapping the layers and was subjected to a pressure of $3 \mathrm{kgf}$ $\mathrm{cm}^{-2}$ for 5 minutes (Eureka Hydraulic press, Hoppe Ind. Ltd., São Paulo SP, Brazil). The juice was treated with pectinase (Pectinex ${ }^{\oplus}$ Ultra Clear, Novozymes, Araucária PR, Brazil) at a rate of $3 \mathrm{~mL}$ $\mathrm{hL}^{-1}\left(45^{\circ} \mathrm{C}, 2 \mathrm{~h}\right)$ (Wosiacki et al., 1989), and after pectinase sedimentation, the juice was poured into containers and frozen

\subsection{Sample preparation}

Samples of juice at different ripening stages were diluted 1:10 (v/v) (Chinnici et al., 2005) with Milli-Q water (type 1) and then filtered through a $0.22 \mu \mathrm{m}$ filter membrane (Waters, Milford, MA, USA). An aliquot of $1.5 \mathrm{~mL}$ of these solutions was placed in vials for the analysis.

\subsection{Equipment and operating conditions}

The chromatographic system coupled to the refractive index detector (HPLC-RI) was equipped with a quaternary pump (Waters 2695 Alliance, Milford MA, USA), degasser, auto injector, and Waters RI 2414 refractive index detector (Milford MA, USA), and the chromatographic data were acquired using the Empower 2 software. The samples obtained as described above were analyzed using an ion exchange column under isocratic condition with type 1 water (Milli-Q Integral ${ }^{\circ}$, Millipore ${ }^{ø}$, São Paulo SP, Brazil). The injection volume was $10 \mu \mathrm{L}$ and the flow rate was $0.5 \mathrm{~mL} \mathrm{~min}^{-1}$. The column temperature was maintained at $80^{\circ} \mathrm{C}$ and the detector at $50^{\circ} \mathrm{C}$. Sample detection was performed by comparing retention times standards.

\subsection{Method validation}

\section{Selectivity}

The refractive index detector (RI) was used to identify the compounds in Fuji Suprema and Lis Gala apple juice samples harvested at different ripening stages. The chromatographic results were evaluated based of retention time and resolution for each analyte and compared with the retention time standards of sucrose $\left(4.0 \mathrm{mg} \mathrm{mL}^{-1}\right)$, D-glucose $\left(2.0 \mathrm{mg} \mathrm{mL}^{-1}\right)$, D-fructose (5.0 $\left.\mathrm{mg} \mathrm{mL}^{-1}\right)$, and $\mathrm{D}$-sorbitol $\left(0.4 \mathrm{mg} \mathrm{mL}^{-1}\right)$.

\section{Linearity}

Linearity was established by triplicate injections of seven (7) different concentrations of the standards obtained by dilution in water of the mixture containing the four sucrose standards: 1.0 to $8.0 \mathrm{mg} \mathrm{mL}^{-1}$; D-glucose, 0.5 to $4.0 \mathrm{mg} \mathrm{mL}^{-1}$; D-fructose, 1.0 to $10.0 \mathrm{mg} \mathrm{mL}^{-1}$, and D-sorbitol, 0.1 to $0.8 \mathrm{mg} \mathrm{mL}^{-1}$. The calibration curve for each sugar was obtained by plotting the concentration of compound versus the area of the respective peaks.

\section{Limit of detection (LOD) and limit of quantification (LOQ)}

The limit of detection (LOD) and the limit of quantification (LOQ) were determined by a method based on analytic curve parameters, according to Equation 1 (Agência Nacional de Vigilância Sanitária, 2003):

$\mathrm{LOD}=\frac{\mathrm{SD} \times 3.3}{\mathrm{~S}} \mathrm{LOQ}=\frac{\mathrm{SD} \times 10}{\mathrm{~S}}$

where: SD: standard deviation of the response; S: slope of the analytical curve.

\section{Precision}

The repeatability of the method was assessed by determining the coefficient of variation (CV\%) of the areas obtained from the injection of seven (7) replicates of the standard solutions (sucrose, $4.0 \mathrm{mg} \mathrm{mL}^{-1}$, D-glucose, $2.0 \mathrm{mg} \mathrm{mL}^{-1}$, D-fructose, $5.0 \mathrm{mg} \mathrm{mL}-1$ and $\mathrm{D}$-sorbitol, $0.4 \mathrm{mg} \mathrm{mL}^{-1}$ ) and of the juices added to this mixture, respectively. In the evaluation of intermediate precision, three (3) replicates were used over three non-consecutive days (Agência Nacional de Vigilância Sanitária, 2003).

\section{Accuracy}

Accuracy was calculated by considering the recovery obtained for each compound at different concentration levels (1.5 and $6.0 \mathrm{mg} \mathrm{mL}^{-1}$ sucrose; 0.75 and $3.0 \mathrm{mg} \mathrm{mL}^{-1} \mathrm{D}$-glucose; 2.0 and $8.0 \mathrm{mg} \mathrm{mL}^{-1} \mathrm{D}$-fructose; 0.15 and $0.6 \mathrm{mg} \mathrm{mL}^{-1}$ D-sorbitol) and were expressed by evaluating the correlation between the results obtained and the net quantity of the compound evaluated. 


\subsection{Data analysis}

Linear models were used to evaluate the sugar standard calibration curves. The lack of fit and statistical significance of the regression equation were determined by analysis of variance (ANOVA), considering the model that showed no lack of fit ( $\mathrm{p} \geq 0.05)$ and statistical significance level $(\mathrm{p}<0.05)$. Homoscedasticity was determined by the Brown-Forsythe test ( $\mathrm{p} \geq 0.05)$, and normality (data and residuals of models) was determined by the Shapiro-Wilk's test. The results of the experimental procedures were evaluated by ANOVA, followed by Tukey's test. All statistical analyses were performed using STATISTICA 8.0 (Statsoft Inc., Tulsa OK, USA).

\section{Results and discussion}

The development and optimization of chromatographic separation of the different sugars present in the apple juice, with an appropriate time frame for analysis using water as the mobile phase, proved efficient. Using water as the mobile phase for the separation of sugars is inexpensive and obviously non-toxic, and it did not generate toxic waste in the analysis.

The selectivity of the compounds examined (Figure 1) was determined by the correlation of the retention times $\left(\mathrm{t}_{\mathrm{r}}\right)$ obtained for the standard sugars and compared with the chromatographic bands of these compounds in the samples, which showed highresolution separations of the compounds.

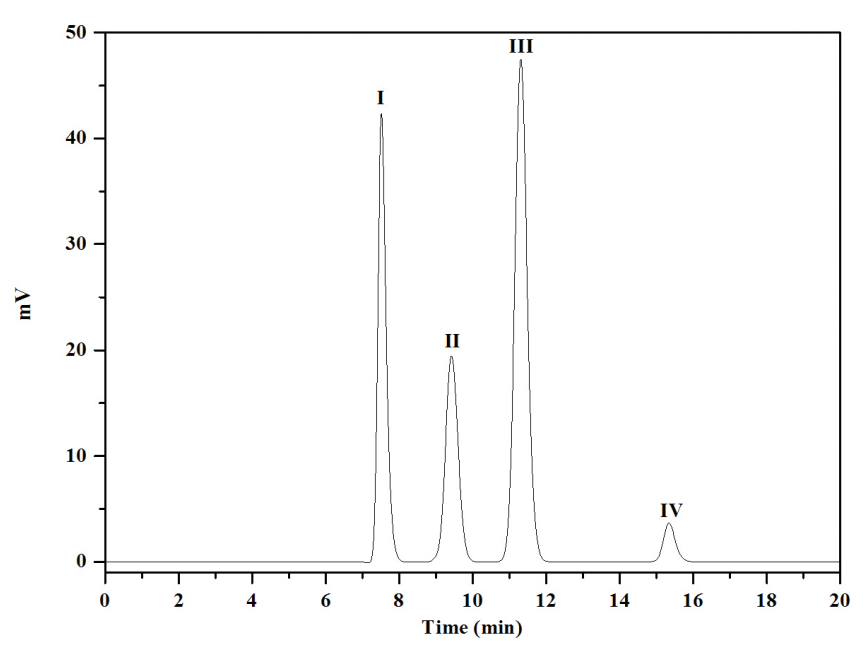

Figure 1. Chromatogram of the standard solutions of (I) sucrose, $4.0 \mathrm{mg} \mathrm{mL}^{-1}$; (II) D-glucose, $2.0 \mathrm{mg} \mathrm{mL}^{-1}$; (III) D-fructose, $5.0 \mathrm{mg} \mathrm{mL}^{-1}$; and (IV) D-sorbitol, $0.4 \mathrm{mg} \mathrm{mL}^{-1}$.
The results obtained for the method validation are shown in Tables 1, 2, and 3. Linearity and range of application of the method were measured by determining the calibration curve by the linear models of sucrose, D-glucose, D-fructose, and D-sorbitol, respectively.

The coefficients of variation (CV\%) of the calibration standards $(\mathrm{n}=7)$ for intra-day precision (repeatability) and inter-day (intermediate) precision ranged from 0.62 to $1.91 \%$ and between 0.29 and $2.87 \%$, respectively (Table 2). Lima et al. (2010) found repeatability values below the maximum acceptable limits for the validation of chromatographic methods. Likewise, the Brazilian legislation that deals with the validation of analytical and bioanalytical methods establishes that CV\% values less than 5 are acceptable (Agência Nacional de Vigilância Sanitária, 2003). Tyagi et al. (2011) concluded that the sugars found in commercial juices also showed stability on different days of analysis with low coefficients of variation.

The limit of detection (LOD) and limit of quantification (LOQ) values obtained for the standards assessed were in the range from 7.56 to $57.86 \mathrm{mg} \mathrm{L}^{-1}$ and 25.21 to $192.88 \mathrm{mg} \mathrm{L}^{-1}$, respectively (Table 2). The limits of detection and quantification values indicate high sensitivity of the system if compared to the values reported by Chinnici et al. (2005) for the detection limits of sucrose, D-glucose, and D-fructose. Muir et al. (2009) determined values of limit of detection and quantification limits for the Sugar Pak ${ }^{\mathrm{TM}}$ column of 1.0 to $50 \mathrm{mg} \mathrm{L}^{-1}$ and $250 \mathrm{mg} \mathrm{L}^{-1}$, respectively, for all of the sugars studied.

The lowest levels of recovery of the sugars sucrose and $\mathrm{D}$-fructose were observed in the juices containing the lowest concentration of the standards added for both Lis Gala and Fuji Suprema apples, respectively. The lowest level of recovery of D-sorbitol was found for the lowest concentration of the standard added to the juice of Fuji Suprema apples. The lowest level of recovery with the addition of the highest concentration of standard to the juices of both cultivars was observed only for D-glucose (Table 3). According to Ribani et al. (2004), dispersion of results increases with the decrease in the concentration of the standard added to the samples. All the results found in the present study are within the acceptable limits established by Brazilian legislation for the validation of chromatographic methods (Agência Nacional de Vigilância Sanitária, 2003).

Figure 2 shows two typical chromatograms of sugars present in apple juice obtained during the validation of the method procedure.

The same developed method was used to determine the sugars evaluated in the samples of the two apple cultivars

Table 1. Linear regression parameters obtained from the sugar standard calibration curves.

\begin{tabular}{|c|c|c|c|c|c|c|c|}
\hline Sugar & Regression Equation & $\mathrm{r}^{2}$ & $\mathrm{r}_{\mathrm{adj}}^{2}$ & p-value ${ }^{*}$ & $\mathrm{p}$-value ${ }^{\star *}$ & $\mathrm{p}$-value $\mathrm{e}^{\star * *}$ & $\mathrm{p}$-value ${ }^{* * * *}$ \\
\hline Sucrose & $y=173,667.76 \cdot x-9,527.23$ & 0.999 & 0.999 & 0.21 & $<0.001$ & 0.10 & 0.05 \\
\hline D-Glucose & $y=235,248.61 \cdot x-2,054.38$ & 0.999 & 0.996 & 0.15 & $<0.001$ & 0.67 & 0.40 \\
\hline D-Fructose & $y=234,307.22 \cdot x-9,592.44$ & 0.999 & 0.999 & 0.11 & $<0.001$ & 0.68 & 0.43 \\
\hline D-Sorbitol & $y=235,702.26 \cdot x-12,391.79$ & 0.999 & 0.996 & 0.13 & $<0.001$ & 0.72 & 0.75 \\
\hline
\end{tabular}

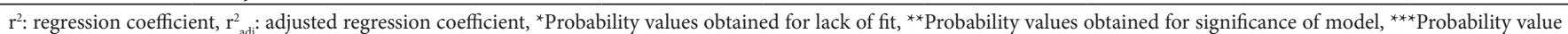
obtained for homoscedasticity by the Brown-Forsythe's test, ${ }^{* * * *}$ Probability value obtained for normality by the Shapiro-Wilk's test. 
Table 2. Validation parameters for the liquid chromatography method.

\begin{tabular}{|c|c|c|c|c|c|c|}
\hline \multirow{2}{*}{ Sugar } & \multirow{2}{*}{$\mathrm{t}_{\mathrm{R}}(\min )$} & \multicolumn{2}{|c|}{ Repeatability } & \multirow{2}{*}{ Intermediate Accuracy } & \multirow{2}{*}{ LOD mg L $\mathrm{L}^{-1}$} & \multirow{2}{*}{ LOQ $\mathrm{mg} \mathrm{L}^{-1}$} \\
\hline & & FSJ & LGJ & & & \\
\hline Sucrose & 7.52 & 0.29 & 0.61 & 0.29 & 54.90 & 183.00 \\
\hline D-Glucose & 9.42 & 0.64 & 0.24 & 2.87 & 16.15 & 53.84 \\
\hline D-Fructose & 11.31 & 0.39 & 0.60 & 0.43 & 57.86 & 192.88 \\
\hline D-Sorbitol & 15.34 & 0.45 & 1.04 & 2.62 & 7.56 & 25.21 \\
\hline
\end{tabular}

Results of repeatability and intermediate accuracy expressed as percentage CV (\%). FJ: Fuji Suprema juice; LG): Lis Gala juice. LOD: limit of detection; LOQ: limit of quantification.

Table 3. Sugar recovery rates (standards) added to the apple juice samples.

\begin{tabular}{ccccc}
\hline & Sucrose & D-Glucose & D-Fructose & D-Sorbitol \\
\hline Standard 1 & $\mathbf{1 . 5 0}$ & $\mathbf{0 . 7 5}$ & $\mathbf{2 . 0 0}$ & $\mathbf{0 . 1 5}$ \\
FSJ & 97.79 & 97.16 & 99.06 & 97.19 \\
LGJ & 94.19 & 85.30 & 99.86 & 101.50 \\
Standard 2 & $\mathbf{6 . 0 0}$ & $\mathbf{3 . 0 0}$ & $\mathbf{8 . 0 0}$ & $\mathbf{0 . 6 0}$ \\
FSJ & 98.73 & 93.84 & 99.42 & 98.30 \\
LGJ & 96.98 & 84.78 & 100.36 & 98.40 \\
\hline
\end{tabular}

FSJ: Fuji Suprema juice; LGJ: Lis Gala juice. Standard 1 and $2\left(\mathrm{mg} \mathrm{mL}^{-1}\right)$. Recovery rate results are expressed as a percentage (\%).

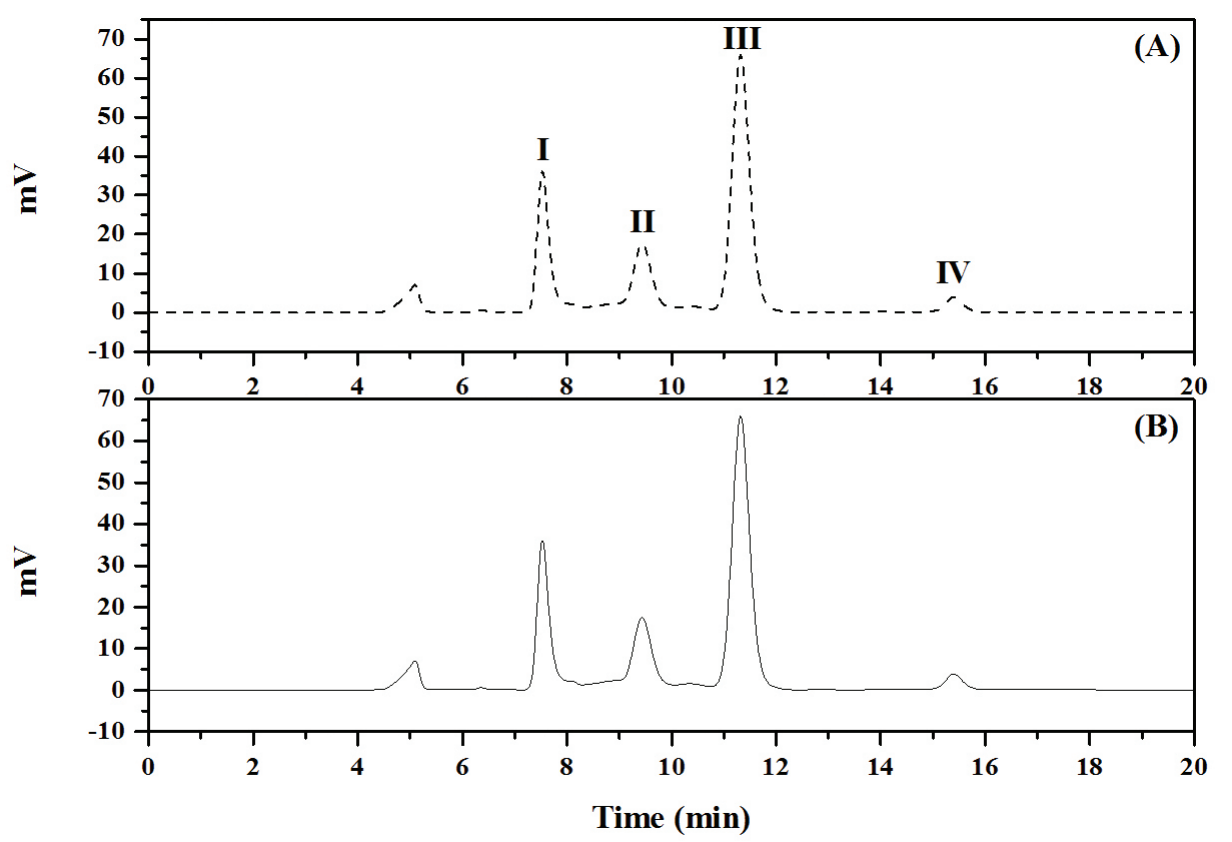

Figure 2. Typical chromatogram of the samples juices from (A) Fuji Suprema and (B) Lis Gala apples. (I) sucrose, (II) D-glucose; (III) and D-fructose (IV) D-sorbitol.

obtained at three different ripening stages. The results of the levels of sugars in the depectinized apple juice of Fuji Suprem and Lis Gala are shown in Table 4.

Hecke et al. (2006) determined the sugar content of 18 different cultivars of apples, and, like Zhang et al. (2010), they found that the major sugars present in apples are sucrose and $\mathrm{D}$-fructose, corroborating the results determined in the present study.

The chromatographic analyses enabled us to establish that at all ripening stages of both apple cultivars, the highest concentration of sugars was found for D-fructose and sucrose. It was also found that in addition to an increase in sucrose concentration, there was also an increase in the relative proportionality of the sugars during ripening. The D-fructose level also increased during ripening but decreased proportionally in relation to the other sugars. Several studies have shown that levels of sucrose, D-glucose, and D-fructose increase with advanced ripening of fruits (Wu et al., 2007). As for the the levels of sugar in the juice, it was also possible to observe that in the pre-ripening period of the Fuji Suprema cultivar, the apples already had levels of $50,86,83$, and $32 \%$ of sucrose, D-glucose, D-fructose, and D-sorbitol, respectively, considering the concentration of juice of senescent apples to be $100 \%$. The same behaviour was observed for the Lis Gala cultivar, which showed $50,62,90$, and $82 \%$ of sugars, respectively, in the pre- 
Table 4. Concentration of sugars (sucrose, D-glucose, D-fructose, and D-sorbitol) in apple juice samples of Lis Gala and Fuji Suprema cultivars in three different ripening stages (pre-ripe, ripe, and senescent).

\begin{tabular}{|c|c|c|c|c|c|}
\hline Samples & Sucrose & D-Glucose & D-Fructose & D-Sorbitol & Total \\
\hline FSP & $\begin{array}{c}2.086^{c} \pm 0.012 \\
(21.18 \%)\end{array}$ & $\begin{array}{c}1.452^{c} \pm 0.001 \\
(14.74 \%)\end{array}$ & $\begin{array}{c}6.080^{c} \pm 0.009 \\
(61.73 \%)\end{array}$ & $\begin{array}{c}0.232^{c} \pm 0.001 \\
(2.35 \%)\end{array}$ & $\begin{array}{c}9.849^{c} \pm 0.019 \\
(100 \%)\end{array}$ \\
\hline FSM & $\begin{array}{c}3.231^{\mathrm{b}} \pm 0.021 \\
(27.50 \%)\end{array}$ & $\begin{array}{c}1.509^{\mathrm{b}} \pm 0.007 \\
(12.84 \%)\end{array}$ & $\begin{array}{c}6.673^{\mathrm{b}} \pm 0.040 \\
(56.78 \%)\end{array}$ & $\begin{array}{c}0.338^{\mathrm{b}} \pm 0.003 \\
(2.88 \%)\end{array}$ & $\begin{array}{c}11.750^{\mathrm{b}} \pm 0.068 \\
(100 \%)\end{array}$ \\
\hline FSS & $\begin{array}{c}4.091^{\mathrm{a}} \pm 0.041 \\
(29.52 \%)\end{array}$ & $\begin{array}{c}1.684^{\mathrm{a}} \pm 0.007 \\
(12.15 \%)\end{array}$ & $\begin{array}{c}7.369^{\mathrm{a}} \pm 0.031 \\
(53.17 \%)\end{array}$ & $\begin{array}{l}0.715^{\mathrm{a}} \pm 0.002 \\
\quad(5.16 \%)\end{array}$ & $\begin{array}{c}13.860^{\mathrm{a}} \pm 0.030 \\
(100 \%)\end{array}$ \\
\hline LGP & $\begin{array}{l}2.423^{C} \pm 0.014 \\
\quad(26.26 \%)\end{array}$ & $\begin{array}{c}0.550^{\mathrm{C}} \pm 0.004 \\
\quad(5.96 \%)\end{array}$ & $\begin{array}{c}6.127^{\mathrm{C}} \pm 0.018 \\
(66.42 \%)\end{array}$ & $\begin{array}{c}0.126^{\mathrm{C}} \pm 0.001 \\
(1.36 \%)\end{array}$ & $\begin{array}{c}9.225^{\mathrm{C}} \pm 0.022 \\
(100 \%)\end{array}$ \\
\hline LGM & $\begin{array}{c}3.665^{\mathrm{B}} \pm 0.028 \\
(32,70 \%)\end{array}$ & $\begin{array}{c}0.659^{\mathrm{B}} \pm 0.012 \\
\quad(5,88 \%)\end{array}$ & $\begin{array}{c}6.707^{\mathrm{B}} \pm 0.069 \\
(59,85 \%)\end{array}$ & $\begin{array}{c}0.177^{\mathrm{A}} \pm 0.003 \\
(1,57 \%)\end{array}$ & $\begin{array}{c}11.207^{\mathrm{B}} \pm 0.045 \\
(100 \%)\end{array}$ \\
\hline LGS & $\begin{array}{c}4.854^{\mathrm{A}} \pm 0.012 \\
(38.14 \%)\end{array}$ & $\begin{array}{c}0.885^{\mathrm{A}} \pm 0.001 \\
(6.95 \%)\end{array}$ & $\begin{array}{c}6.833^{\mathrm{A}} \pm 0.005 \\
(53.69 \%)\end{array}$ & $\begin{array}{c}0.154^{\mathrm{B}} \pm 0.001 \\
(1.22 \%)\end{array}$ & $\begin{array}{c}12.726^{\mathrm{A}} \pm 0.017 \\
(100 \%)\end{array}$ \\
\hline
\end{tabular}

Means \pm standard deviation. Results are expressed in g/100 mL; FP: pre-ripe Fuji Suprema; FM: mature Fuji Suprema; FS: senescent Fuji Suprema; LGP: pre-ripe Lis Gala; LGM: mature Lis Gala; LGS: senescent Lis Gala. Values in the same row followed by similar letters are not significantly different (Tukey, p $>0.05$ ). Lowercase letters refer to Fuji Suprema and uppercase refer to Lis Gala.

maturation stage. Thus, it can be seen that most of the sugars are formed during the development of the fruit and that during the ripening, there is an increase due to the transformation of starch into soluble sugars (Duque et al., 1999). According to Zhang et al. (2010), the accumulation of sugars occurs throughout the development of the fruit and continues until the time of harvest. During growth and fruit maturation period, the starch degrades (considered to be a form of temporary storage of sugars) into soluble sugars, acids, and parietal components accompanied by a high accumulation of water. Finally, during the last period of slow growth, intensive metabolic changes occur concomitantly with maturation. The last two periods of growth are therefore crucial for the final accumulation of sugar in the fruit. From a physiological standpoint, the concentration of sugars in fruits is a result of several interrelated physiological processes, such as fluxes of carbon and water entering the fruit (Duque et al., 1999; Prudent et al., 2011).

\section{Conclusion}

The method developed using HPLC-RI proved a fast and efficient method for quantification of sugars (sucrose, D-glucose, D-fructose, and D-sorbitol) present in apple juice. Sample preparation was simple, requiring only dilution and filtration before injection, and the mobile phase (water) used generated small amount of nontoxic residues. All parameters of the validation steps (sensitivity, linearity, precision, and accuracy) were in accordance with Brazilian legislation. The use of this method to evaluate the sugars present in samples of apples at different ripening stages showed that the increase in sugars in juice takes place with with raw material ripening, and more than $70 \%$ of total sugars were already present in the juice of fruits processed at the pre-ripe stage.

\section{Acknowledgements}

The authors are deeply grateful for the financial support provided by UEPG, EPAGRI, CAPES, FINEP and CNPq and for the research scholarships granted to Ivo Mottin Demiate, Alessandro Nogueira, and Gilvan Wosiacki by CNPq.

\section{References}

Acosta-Montoya, Ó., Vaillant, F., Cozzano, S., Mertz, C., Pérez, A. M., \& Castro, M. V. (2010). Phenolic content and antioxidante capacity of tropical highland blackberry (Rubus adenotrichus Schltdl.). during three edible maturity stages. Food Chemistry, 119, 1497-1501. http:// dx.doi.org/10.1016/j.foodchem.2009.09.032

Agência Nacional de Vigilância Sanitária - Anvisa. (2003). Resolução da Diretoria Colegiada 899, de 29/05/2003. Guia Sanitário. Brasília: Ministério da Saúde. Retrieved from http://portal.anvisa.gov.br.

Associação Brasileira de Produtores de Maçã - ABPM. (2007). Dados estatísticos sobre a cultura da macieira. Retrieved from http://www. abpm.org.br.

Brasil. (2009). Decreto $n^{\circ} 6871$ de 04 de junho de 2009. Regulamenta a lei no 8918 de 14 de julho de 1994. Dispõe sobre a padronização, a classificação, o registro, a inspeção, a produção e a fiscalização de bebidas. Diário Oficial da República Federativa do Brasil, Brasília.

Cerdán-Calero, M., Sendra, J. M., \& Sentandreu, E. (2012). Gas chromatography coupled to mass spectrometry analysis of volatiles, sugars, organic acids and aminoacids in Valencia late orange juice and reliability of the automated mass spectral deconvolution and identification system for their automatic identification and quantification. Journal of Chromatography A, 1241, 84-95. http:// dx.doi.org/10.1016/j.chroma.2012.04.014

Chávez-Servín, J. L., Castellote, A. I., \& López-Sabater, M. C. (2004). Analysis of mono- and disaccharides in milk-based formulae by high-performance liquid chromatography with refractive index detection. Journal of Chromatography A, 1043, 211-215. http:// dx.doi.org/10.1016/j.chroma.2004.06.002

Chinnici, F., Spinabelli, U., Riponi, C., \& Amati, A. (2005). Optimization of the determination of organic acids and sugars in fruit juices by ion-exclusion liquid chromatography. Journal of Food Composition and Analysis, 18, 121-130. http://dx.doi.org/10.1016/j. fca.2004.01.005

Duque, P., Barreiro, M. G., \& Arrabaça, J. D. (1999). Respiratory metabolism during cold storage of apple fruit I. Sucrose metabolism and glycolysis. Physiologia Plantarium, 107, 14-23. http://dx.doi. org/10.1034/j.1399-3954.1999.100103.x

Garai-Ibade, G., Irastorza, A., Dueñas, M. T., Martín-Álvarez, P. J., \& Moreno-Arribas, V. M. (2012). Evolution of amino acids and biogenic amines in natural ciders as a function of the year and 
the manufacture steps. International Journal of Food Science \& Technology. http://dx.doi.org/10.1111/j.1365-2621.2012.03198.x

Hecke, K., Herbinger, K., Veberic, R., Trobec, M., Troplak, H., Stampar, F., Keppel, H., \& Grill, D. (2006). Sugar-, acid- and phenol contents in apple cultivars from organic and integrated fruit cultivation. European Journal of Clinical Nutrition, 60, 1136-1140. http://dx.doi. org/10.1038/sj.ejcn.1602430

Kawashima, L. M., \& Soares, L. M. V. (2006). Incidencia de fumonisina $B_{1}$, aflatoxinas $B_{1}, B_{2}, G_{1}$ e $G_{2}$, ocratoxina $A$ e zearalenona em produtos de milho. Ciência e Tecnologia de Alimentos, 26, 516-521. http://dx.doi.org/10.1590/S0101-20612006000300005

Lima, L. L. A., Schuler, A., Guerra, N. B., Pereira, G., Lima, T. L. A., \& Rocha, H. (2010). Otimização e validação de método para determinação de ácidos orgânicos em vinhos por cromatografia líquida de alta eficiência. Química Nova, 33, 1186-1189. http:// dx.doi.org/10.1590/S0100-40422010000500032

Llamas, N. E., Di Nezio, M. S., \& Band, B. S. F. (2011). Flow-injection spectrophotometric method with on-line photodegradation for determinarion of ascorbic acid and total sugars in fruit juices. Journal of Food Composition and Analysis, 24, 127-130. http://dx.doi. org/10.1016/j.fca.2010.06.002

Llorente, D. D., Abrodo, P. A., González-Álvarez, J., De la Fuente, E. D., Alonso, J. J. M., Álvarez, M. D. G., \& Gomis, D. B. (2012). A new analytical method to volatile compounds in cider apples: Application to evaluate the starch index. Food and Bioprocess Technology. http://dx.doi.org/10.1007/s11947-012-0879-5

Ma, M., Luo, X., Chen, B., Su, S., \& Yao, S. (2006). Simultaneous determination of water-soluble and fat-soluble synthetic colorants in foodstuff by high-performance liquid chromatography-diode array detection-electrospray mass spectrometry. Journal of Chromatography A, 1103, 170-176. http://dx.doi.org/10.1016/j. chroma.2005.11.061

Muir, J. G., Rose, R., Rosella, O., Liels, K., Barrett, J. S., Shepherd, S. J., \& Gibson, P. R. (2009). Measurement of short-chain carbohydrates in common Australian vegetables and fruits by high-performance liquid chromatography (HPLC). Journal of Agricultural and Food Chemistry, 57, 554-565. http://dx.doi.org/10.1021/jf802700e

Prudent, M., Lecomte, A., Bouchet, J., Bertin, N., Causse, M., \& Génard, M. (2011). Combining ecophysiological modeling and quantitative trait locus analysis to identify key elementary processes underlying tomato fruit sugar concentration. Journal of Experimental Botany, 62, 907-919. http://dx.doi.org/10.1093/jxb/erq318

Puoci, F., Curcio, M., Cirillo, G., Iemma, F., Spizzirri, U. G., \& Picci, N. (2008). Molecularly imprinted solid-phase extraction for cholesterol determination in cheese products. Food Chemistry, 106, 836-842. http://dx.doi.org/10.1016/j.foodchem.2007.06.043

Ribani, M., Bottoli, C. B. G., Collins, C. H., Jardim, I. C. S. F., \& Melo, L. F. C. (2004). Validação de métodos cromatográficos e eletroforéticos. Química Nova, 27, 771-780. http://dx.doi.org/10.1590/S010040422004000500017

Rodriguez, R. S. J., Fernández-Ruiz, V., Cámara, M., \& Sánchez-Mata, M. C. (2012). Simultaneous determination of vitamin $B_{1}$ and $B_{2}$ in complex cereal foods, by reverse phase isocratic HPLC-UV. Journal of Cereal Science, 55, 293-299. http://dx.doi.org/10.1016/j. jcs.2011.12.011

Rodriguez-Saona, L. E., Fry, F. S., McLaughlin, M. A., \& Calvey, E. M. (2001). Rapid analysis of sugars in fruit juices by FT-NIR spectroscopy. Carbohydrate Research, 336, 63-74. http://dx.doi. org/10.1016/S0008-6215(01)00244-0

Shui, G., \& Leong, L. P. (2002). Separation and determination of organic acids and phenolics compounds in fruit juices and drinks by highperformance liquid chromatography. Journal of Chromatography A, 977, 89-96. http://dx.doi.org/10.1016/S0021-9673(02)01345-6

Soga, T., \& Serwe, M. (2000). Determination of carbohydrates in food samples by capillary electrophoresis with indirect UV detection. Food Chemistry, 69, 339-344. http://dx.doi.org/10.1016/S03088146(00)00044-3

Speek, A. J., Temalilwa, C. R., \& Schrijver, J. (1986). Determination of $\beta$-carotene content and vitamin A activity of vegetables by highperformance liquid chromatography and spectrophotometry. Food Chemistry, 19, 65-74. http://dx.doi.org/10.1016/03088146(86)90128-7

Tyagi, G., Jangir, D. K., Singh, P., Mehrotra, R., Ganesan, R., \& Gopal, E. S. R. (2011). Rapid determination of main constituents of packed juices by reverse phase-high performance liquid chromatography: an insight in to commercial fruit drinks. Journal of Food Science and Technology, 45, 1-9. http://dx.doi.org/10.1007/s13197-011-0502-1

Vidotti, E. C., Costa, W. F., \& Oliveira, C. C. (2006). Development of a green chromatographic method for determination of colorants in food samples. Talanta, 68, 516-521. http://dx.doi.org/10.1016/j. talanta.2005.01.059

Villamiel, M., Martínez-Castro, I., \& Corzo, A. O. N. (1998). Quantitative determination of carbohydrates in orange juice by gas chromatography. European Food Research and Technology, 206, 48-51. http://dx.doi.org/10.1007/s002170050212

Wosiacki, G., Namiuchi, N. N., Cerebelli, M. I., Sataque, E. Y., Sinciheri, V. L., Oliveira, T. C., \& Cesar, E. O. (1989). Estabilidade do suco clarificado de maçãs. Parte I-Processo de obtenção do suco de maçãs. Arquivo de Biologia e Tecnologia, 32, 775-786

Wosiacki, G., Nogueira, A., Denardi, F., \& Vieira, R. G. (2007). Sugar composition of depectinized apple juices. Semina: Ciências Agrárias, $28,645-652$

Wu, J., Gao, H., Zhao, L., Liao, X., Chen, F., Wang, Z., \& Hu, X. (2007). Chemical compositional characterization of some apple cultivars. Food Chemistry, 103, 88-93. http://dx.doi.org/10.1016/j. foodchem.2006.07.030

Zhang, Y., Li, P., \& Cheng, L. (2010). Developmental changes of carbohydrates, organic acids, amino acids, and phenolic compounds in 'Honeycrisp' apple flesh. Food Chemistry, 123, 1013-1018. http:// dx.doi.org/10.1016/j.foodchem.2010.05.053

Zielinski, A. A. F., Staron, E. A., Rebelato, F. C. A., Nogueira, A., \& Wosiacki, G. (2012). Blueberry extract to enhance the antioxidant potential of apple juice. Fruit Processing, 3, 94-99. 